\title{
A CHARGE COMO DOCUMENTO: \\ uma proposta a partir da análise documentária
}

\section{THE POLITICAL CARTOON AS DOCUMENT:}

\author{
a proposal from the subject analysis
}

Thulio Pereira Dias Gomes ${ }^{1}$

Rosali Fernandez de Souza ${ }^{2}$

\section{RESUMO}

Trata da caracterização da charge como documento no escopo da organização do conhecimento. 0 objetivo é investigar 0 caráter informativo da charge a partir da aplicação das variáveis da análise documentária. Seleciona a análise documentária como a corrente teórica do tratamento temático da informação, no âmbito da Ciência da Informação, para efeitos de análise. Propõe que as variáveis da análise documentária de charge sejam: a) a estrutura narrativada charge; b) as informações brutas presentes na charge; c) a terminologia da área; d) instituições de custódia da charge; e) os usuários da charge e f) o estoque do conhecimento anterior do analista e sua formação ideológica. Conclui que a análise documentária é uma vertente possível de olhar a charge como documento viabilizando o seu tratamento temático, propondo variáveis para a análise documentária de charges no âmbito de sistemas de recuperação da informação.

Palavras-chave: Análise documentária. Charge. Documento.

\begin{abstract}
This paper deals with the characterization of the charge as a document within the scope of the knowledge organization. The objective is to investigate the informative character of the political cartoon from the application of the variables of the subject analysis. It selects subject analysis as the theoretical approach of thematic treatment of information, in the scope of Information Science, for the purposes of analysis. This paper proposed the variables of the analysis of political cartoon are: a) the narrative estructure of political cartoon; b) the information present in the political cartoon; c) the terminology of the area; d) custody institutions for political cartoons; e) the users of the political cartoon and f) the stock of the previous knowledge of the analyst and his ideological formation. It concludes the subject analysis is a possible approach for assay at the political cartoon as a document, enabling its thematic treatment, proposing variables for the subject analysis of political cartoons in the scope of information retrieval systems.
\end{abstract}

Keywords: Document. Political cartoon. Subject analysis.

Artigo submetido em 02/03/2020 e aceito para publicação em 28/03/2020

1 Bibliotecário-documentalista da Biblioteca Universitária de Campos dos Goytacazes. Universidade Federal Fluminense, Brasil. ORCID: https://orcid.org/0000-0002-2817-1253. E-mail: thuliogomes@id.uff.br

2 Pesquisadora titular do Instituto Brasileiro de Informação em Ciência e Tecnologia, Brasil. ORCID: http://orcid.org/0000-0002-08907999. E-mail: rosali@ibict.br 


\section{INTRODUÇÃ̃}

Os elementos referenciais básicos de um sistema de informação são os documentos e a comunidade de possíveis/potenciais usuários a que se destinam. A viabilização desse sistema compreende operações fundamentais de organização, de representação e de recuperação da informação, notadamente aquelas embasadas no tratamento temático da informação.

A charge como documento pode incorporar uma diversidade de formas no escopo da organização do conhecimento. Ao refletir sobre o caráter informativo da charge, consideramos possível identificar variáveis próprias de análise da charge enquanto documento quanto ao o conteúdo temático que representam.

Considerando as correntes teóricas do tratamento temático da informação no escopo da organização do conhecimento no âmbito da Ciência da Informação, decidimos partir das variáveis da análise documentária aplicando-as especificamente à charge enquanto documento no contexto de sistemas de recuperação da informação.

Concluímos sobre a viabilidade de tal análise na identificação de parâmetros para a caracterização da charge como documento e do tratamento do conteúdo informativo para busca.

\section{DESENVOLVIMENTO}

Guimarães (2009) observa, no universo do tratamento temático da informação, três vertentes teóricas que subsidiam as práticas nesse domínio. A primeira é a catalogação de assunto (subject cataloguing), de matriz estadunidense, cuja tônica reside na construção do catálogo de assunto enquanto produto do tratamento temático da informação em bibliotecas. Surgida no contexto dos centros de documentação e das bibliotecas especializadas, a segunda abordagem é a indexação (indexing), de matriz inglesa, e que enfoca a provisão de instrumentos para a busca de informação na perspectiva da dupla dimensão entre o documento e 0 usuário, que é representada pela recuperação da informação. A análise documentária (analyse documentaire), de matriz francesa, é a terceira vertente teórica do tratamento temático da informação e sua preocupação recai sobre os procedimentos da organização do conhecimento e da informação, ou seja, na identificação e na descrição de suas etapas.

Segundo Cunha (1990, p. 59), durante muito tempo, os métodos de organização da informação "foram considerados como operações empíricas de 'bom senso' pelas quais se 
atribuía, a um texto/documento qualquer, uma ou várias palavras-chave destinadas a facilitar a recuperação, no momento da pesquisa sobre um dado tema". Durante esse período, Guimarães (2009, p. 112) ressalta que não se tinha "exatamente claro como o processo de determinação de assunto efetivamente ocorre". Hjørland (2008) declara que a prática tradicional de organização do conhecimento tem sido uma atividade de cunho prático, sem consistência teórica. Nesse contexto, a análise documentária surge como uma das iniciativas em sistematizar os processos de organização do conhecimento.

\subsection{Análise documentária}

A análise documentária surge frente à preocupação com o desenvolvimento de referenciais teórico-metodológicos para o processo de organização da informação. A literatura destaca, durante o desenvolvimento inicial, os estudos de forte matriz linguística dos franceses JeanClaude Gardin e Maurice Coyaud. A análise documentária francesa tem importantes reflexos na Espanha, a partir de trabalho de Antonio Luis García Gutierrez, de Félix Sagredo Fernández e de José Maria Izquierdo Arroyo. No Brasil, através de pesquisadores,como Johanna Wilhelmina Smit e Marilda Lopes Ginez de Lara, do Grupo TEMMA, grupo de pesquisa afiliado à Universidade de São Paulo (USP), com os estudos sobre linguística documentária (GUIMARÃES,2009; LARA, 2011; SMIT, 2012).

A análise documentária é definida sob diversos aspectos por diferentes autores. É considerada como "uma atividade metodológica específicano interior da documentação, que trata da análise, síntese e representação da informação, com o objetivo de recuperá-la e disseminá-la" (CINTRA et al., 1994, p.24). Para Coyaud 3 , citado por Lara (2011), a análise documentária é, primeiramente, uma operação de reconhecimento das unidades lexicais que representam as noções importantes de um documento. Gardin (1973) apresenta a análise documentária como um conjunto de procedimentos efetuados com a finalidade de expressar o conteúdo dos documentos científicos, sob formas destinadas a facilitar a recuperação da informação. Para García Gutierrez (1990), a análise documentária consiste em extrair as ideias centrais de um documento com o fim de disponibilizá-lo para sua recuperação mediante representações sintéticas.

3 COYAUD, M. Introduction a I'étude des languages documentaires. Paris: C. Klincksieck, 1996. p. 8. 
Araújo Júnior (2007) reconhece a análise documentária como parte precípua do processo por que passa um documento em uma base de dados. Acrescenta que após ser selecionado para inclusão em uma base de dados, explica Araújo Júnior (2007), o documento deverá passar por um processo de análise de seus conteúdos, para que esses possam ser representados de modo a operacionalizar a sua posterior recuperação.

Cunha (1990) identifica duas fases no processo de análise documentária: análise e síntese. Nessa mesma direção, Guimarães (2003) esclarece que a etapa analítica se subdivide em: leitura técnica do documento, visando a identificar as partes com maior conteúdo temático, e identificação de conceitos mais significativos tematicamente. Especifica que a etapa sintética se subdivide em três momentos: seleção de conceitos, pela qual os assuntos são postos em categorias (principais, secundários e periféricas); condensação documentária, referente à elaboração de um resumo para 0 documento, e representação documentária, pela qual o conteúdo temático do documento é traduzido em linguagem de indexação.

Kobashi (1996, p. 9) lança mão do termo "informação documentária" em sua proposta de delineamento de fases para análise documentária. Lara considera que a informação documentária se refere ao resultado da análise documentária, isto é, a um produto documentário designador de um conteúdo sob a forma de resumos e/ou descritores e que visa ao estabelecimento de uma comunicação (LARA, 2002).

Kobashi (1996), então, esquematiza três fases para a elaboração de informações documentárias, que, segundo a autora, são válidas independentemente do corpus documental a ser analisado ou do sistema informativo documental no interior do qual se realizam. A primeira fase corresponde à leitura do texto. A segunda fase consiste na seleção, no texto lido, do conteúdo informacional pertinente a usos determinados. A terceira fase se refere à representação das informações selecionadas, de modo a torná-las documentariamente manipuláveis.

Não obstante existirem operações gerais para análise documentária, Lara (1993) elenca, para o processo global da análise documentária, variáveis de ordens endógena e exógena. De acordo com a autora, esse processo documentário varia de acordo com: a) a estrutura do texto original; b) a informação bruta presente neste mesmo texto; c) 0 estado de sistematização metodológica e terminológica da área em questão; d) a instituição na qual o processo se desenvolve; e) 0 usuário da informação documentária; f) 0 estoque de conhecimento anterior do documentalista e sua formação ideológica. Essas variáveis do processo geral de análise documentária propostas por Lara (1993) são ilustradas na figura 1. 
Figura 1 - Variáveis do processo global da análise documentária propostas por Lara (1993)

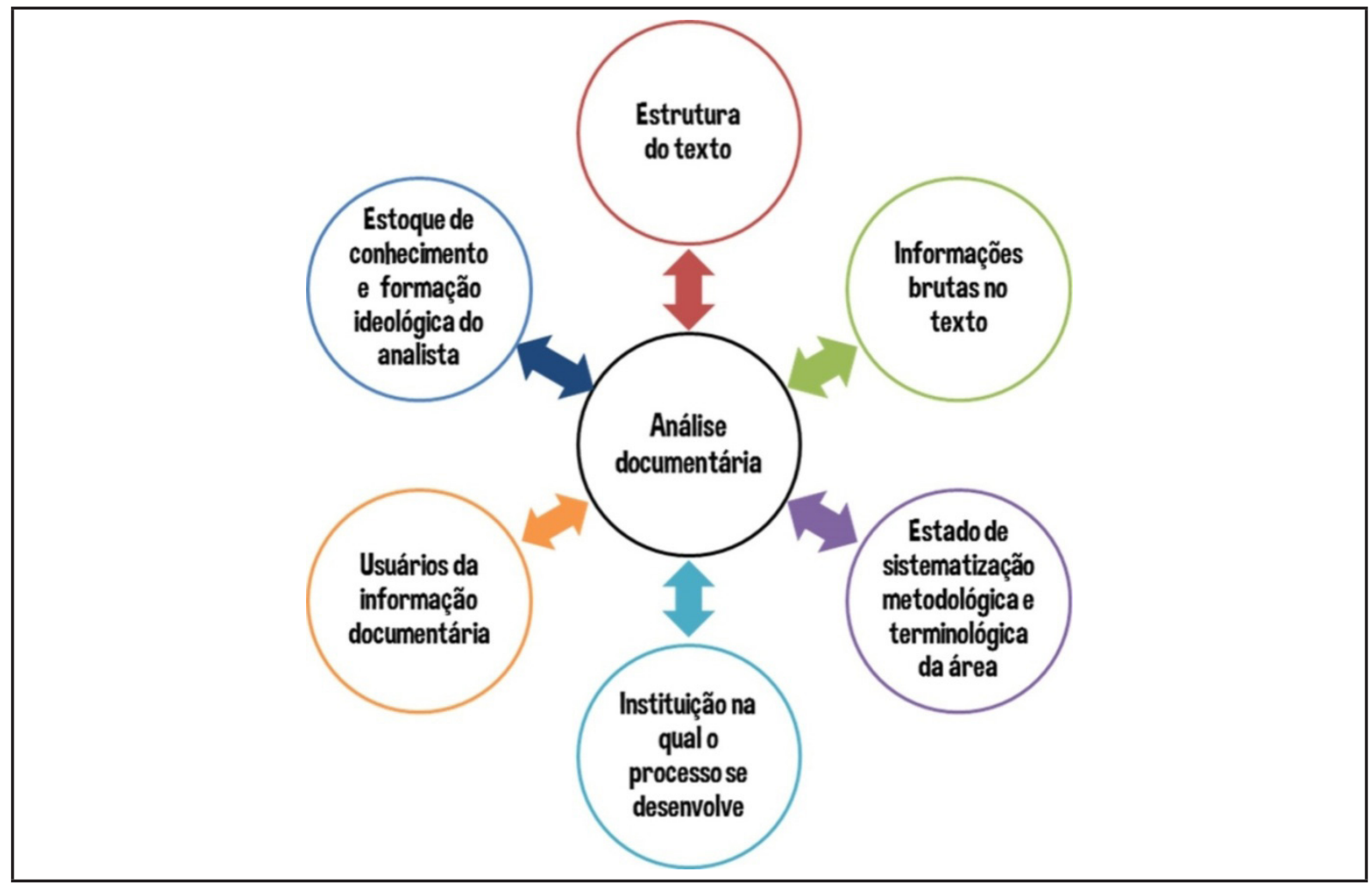

Fonte: GOMES (2015, p. 134)

Como observado na Figura 1, as variáveis propostas por Lara (1993) para a análise documentária abarcam os elementos referencias de sistemas de recuperação da informação como especificado a seguir. 0 documento em si é considerado na 'estrutura do texto' e nas 'informações brutas no texto'. 0 tratamento da informação é sinalizado no 'estado de sistematização metodológica e terminológica da área' do conhecimento que representa. Continua com a especificação do para que na 'instituição na qual o processo de desenvolve' enquanto caracterização do sistema de informação em que está inserido o documento. 0 para quem é especificado como os 'usuários da informação documentária'. 0 profissional da informação é considerado no 'estoque de conhecimento e formação ideológica do analista' do documento. Com base nessas variáveis da análise documentária proposta por Lara, procedeu-se a caracterização da charge como documento.

\subsection{Análise documentária de charges}

A discussão a respeito da análise documentária na perspectiva de suas variáveis permite a proposta de uma adaptação às charges. Neste sentido, propõe-se que as variáveis da análise 
documentária de charge sejam: a) a estrutura narrativa da charge; b) as informações brutas presentes na charge; c) a terminologia da área; d) instituições de custódia da charge; e) os usuários da charge e f) 0 estoque do conhecimento anterior do analista e sua formação ideológica. Essas variáveis são ilustradas no esquema apresentado na figura 2 e discutidas a seguir.

Figura 2 - Variáveis do processo global da análise documentária de charge proposta e ilustrada por Gomes em base das variáveis da análise documentária de documentos proposta por Lara

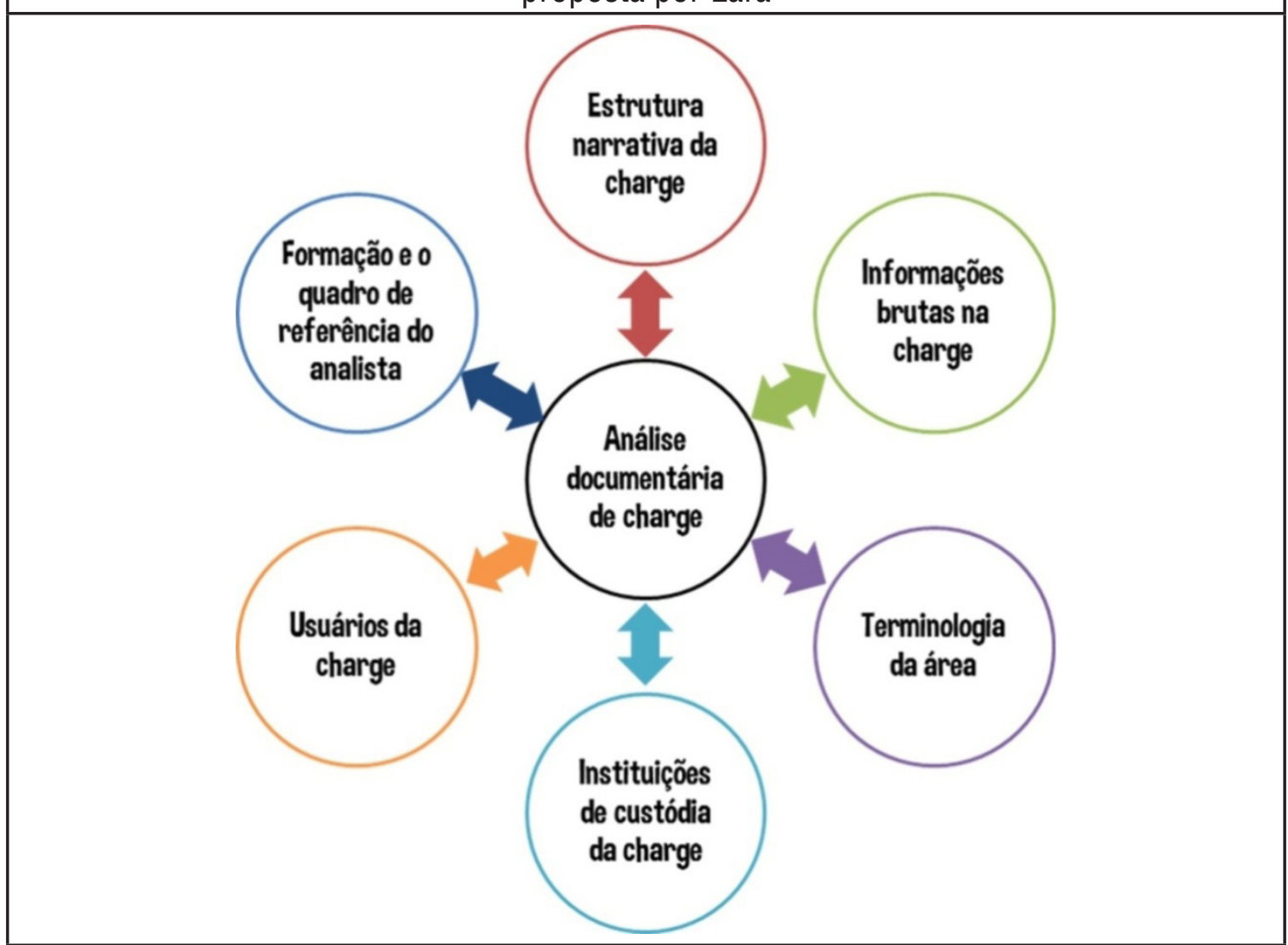

Fonte: GOMES (2015, p 135)

\subsubsection{A estrutura narrativa da charge}

Segundo Lara (1993), a estrutura textual é o reflexo do arranjo utilizado pelo autor para a apresentação das informações. De acordo com Mollica e Guedes (2013), na enunciação, os falantes embalam as informações por meio de opções linguísticas e de estruturas da linguagem em contextos de fala e de escrita. As autoras citadas a seguir consideram que o reconhecimento dessas estruturas favorece a compreensão do fluxo da informação durante a leitura do texto. (CUNHA, 1990; FUJITA, 2004; KOBASHI,1996; MOLLICA; GUEDES, 2013). 
Em termos de análise documentária de charge, a dimensão textual, porém, não esgota as principais características desta, que são a relação com o contexto de enunciação e a linguagem sincrética (FLÔRES, 2002; GOMES; GUEDES; SANTOS, 2013). Torna-se, portanto, necessária a transposição do nível textual para um nível mais abrangente, o narrativo. Na dimensão da narrativa, observa-se a temporalidade, ainda que estática, na charge. A narrativa da charge é sustentada pela enunciação, pelo que é explicitamente enunciado ou pela indicação que o desenho nos dá sobre o que aconteceu antes ou do que acontecerá depois da situação desenhada (VIEIRA, 2001). A figura 3 pode ser considerada para exemplificar a dimensão narrativa da charge.

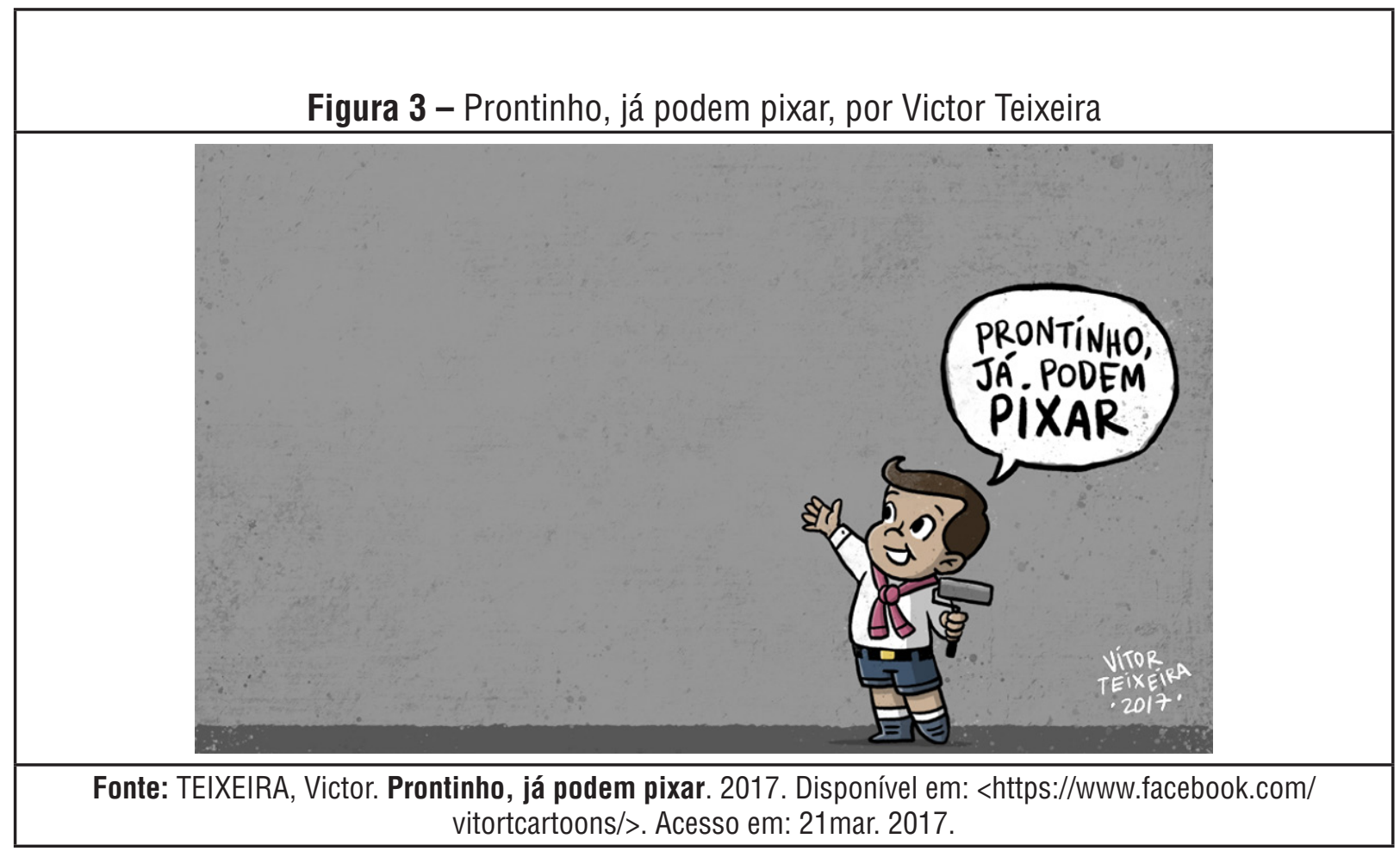

A charge da figura 3 refere-se ao prefeito de São Paulo ao instituir o Programa Cidade Linda 4 . Na cena estática, apontam-se elementos da sequência narrativa ${ }^{5}$. É possível identificar um estado inicial

4 João Doria Júnior (São Paulo, 16 de dezembro de 1957), prefeito de São Paulo (2017-2018), instituiu no segundo dia de seu mandado o Programa Cidade Linda. Segundo a Secretaria Especial de Comunicação da Prefeitura de São Paulo, a ação contempla serviços de manutenção de logradouros, conservação de galerias e pavimentos, retirada de faixas e cartazes, limpeza de monumentos, recuperação de praças e canteiros, poda de árvores, manutenção de iluminação pública, reparo em sinalização de trânsito, limpeza de pixações, troca de lixeiras e reparo de calçadas. Nas primeiras semanas de realização desse programa, o prefeito declarou guerra aos pixadores, grafiteiros e artistas de rua. Vestido com roupas de funcionários da limpeza municipal, o prefeito e sua equipe cobriram de tinta cor cinza muros da Avenida 23 de Maio, lugar conhecido mundialmente por seus grafites. A ação prosseguiu na capital paulista durante os dias seguintes. A ação higienista do prefeito, além de trazer revolta entre pichadores e grafiteiros, levantou a questão sobre o que é vandalismo, arte e expressão urbanas.

5 Adam (1985 apud VIEIRA, 2011) defende que o mais importante na sequência narrativa mínima é a passagem e a transformação de um estado inicial em um estado final, havendo macroposições narrativas intermediárias que funcionam como elementos de garantia nessa transformação. Com esta ideia, Adam propõe um abstrato modelo narrativo. 
que passa por uma transformação até chegar a um estado final. 0 estágio inicial poderia ser 0 muro antes de ser pintado de cinza. A transformação foi a pintura do muro em cor cinza. 0 estágio final é 0 personagem Dorinha declarando “Prontinho, já podem pixar!”. Observa-se que esta análise é realizada em base de uma estrutura narrativa mínima.

A identificação de todos os elementos da charge, todavia, não é necessária para a construção de narrativas por aquele que vê a imagem. Na charge da figura 3, por exemplo, não há nenhuma referência direta ao episódio a que se refere. Sem a identificação dos elementos iconográficos, a charge poderia ser vista como cartum. Considerando diversas políticas higienistas contra o pixo em diversas cidades no mundo, supõe-se que alguém, ao ver a imagem, poderia identificar o contexto em outras cidades diferentes de São Paulo. 0 tom crítico também poderia ser esvaziado ou estendido se ao personagem fosse atribuído um significado mais universal de alguém que pintou um muro na intenção de apagar pixos e grafites. Nessa situação, o sentido dado à narrativa seria outro diferente da situação a que se refere à charge, mas não menos possível.

Outra questão que diz respeito à estrutura da charge é o conflito entre linguagens da charge e do sistema de informação. Teixeira (2005, p. 56) aponta que a "imagem é atravessada pelo discurso da fala, de modo tal que sua visibilidade depende de sua textualidade". Esta relação entre visibilidade e fala é também encontrada nas palavras de Foucault (1999, p. 11) quando declara que "por mais que se diga o que se vê, o que se vê não se aloja no que se diz". Para este autor, o lugar das palavras não é 0 lugar descortinado pelos olhos, mas é um lugar definido pelas sucessões da sintaxe.

Não há, assim, como traduzir efetivamente os conteúdos da charge, e de qualquer outra imagem e até mesmo textos, para a linguagem documentária. Os resumos, as legendas e os descritores não são eficazes para dar conta do conteúdo da charge e dos demais documentos, tampouco das possibilidades de significação e de utilização. Afinal, "analisar uma imagem significa, quer queiramos quer não, 'traduzir' certos elementos desta imagem de um código icônico para um código verbal” (SMIT, 1989, p. 105). É possível, então, falar de uma perda semântica inevitável na tradução do conteúdo dos documentos para as linguagens documentárias, uma vez se tratar de transcodificação, uma mudança de um código para outro. Em outras palavras, o conteúdo de uma charge não pode ser efetivamente traduzido para um texto documentário, sem que haja uma redução de sentidos na tradução da linguagem sincrética da charge para a linguagem documentária.

Sob a perspectiva do outro lado de um sistema de informação, também é possível questionar como os usuários do sistema podem traduzir suas necessidades de informação, em vista das restrições da linguagem do sistema. 
A investigação de estrutura da charge pode indicar possibilidades de categorização de charges. Algumas categorias foram sugeridas por autores como Gawryszewski (2008) e Peláez Malagón (2003) com a intenção de estabelecer definições de caricatura e de charge. Mollica e Guedes (2013) falam da viabilidade com fins didáticos e de pesquisa do agrupamento de gêneros discursivos. A categorização de charge, nesse sentido, pode ser algo que contribua para a sua análise documentária, sobretudo aquela que envolve a representação descritiva. 0 estabelecimento de categorias de charge poderá apontar a necessidade de desenvolvimento de metodologias distintas para a análise documentária das possíveis tipologias de charge (GOMES, 2013).

\subsubsection{A "informação bruta” na charge}

As informações brutas presentes no texto, conforme Lara (1993), se referem às mensagens mais significativas. Segundo Vanoye (2002), as informações brutas são integradas por elementos referenciais, ou seja, elementos que remetam explicitamente ao espaço e ao tempo em que a mensagem é veiculada. Para o autor, os elementos referenciais definem as informações de base da mensagem. As informações brutas e objetivas no texto configuram uma das variáveis do processo de análise documentária da charge.

Entretanto, a leitura da charge pode falhar na identificação de conteúdos informativos, conforme os estudos de Gomes, Guedes e Santos (2013) e de Wu (2013). Assim, são necessários recursos teóricos e metodológicos que favoreçam a identificação desses elementos referenciais da charge, isto é, as informações contidas na charge, condições de sua informatividade.

Segundo Lara (2008), o conceito de informatividade se origina na lingüística textual e, em sua versão contemporânea, destaca o fato de a compreensão de um texto depender do conhecimento de outros textos. No tocante ao paradigma hermenêutico da Ciência da Informação, relacionado à perspectiva domínio-analítica, a informatividade depende da relação entre a relevância da mensagem comunicada e o conhecimento prévio de certo indivíduo e/ou do conhecimento compartilhado por determinada comunidade discursiva ou laboral. Para que algo seja considerado informação, é necessária uma pré-estrutura de conhecimento capaz de contextualizar e de interpretar a mensagem, gerando uma nova estrutura de conhecimento. A informação, assim, constitui-se no conhecimento em prática e está relacionada à novidade e à relevância do conteúdo das mensagens (CAPURR0, 2007; CAPURR0; HJØRLAND, 2007 [2003]). Em outras palavras, "a informação é, mais precisamente, a articulação de uma compreensão prévia do mundo comum compartilhado." (CAPURR0, 1991, p. 86). 
Recorre-se também à noção de informação da linguística documentária. Segundo a proposta de Lara (2006 apud LARA, 2008), a informação é o "resultado de uma construção institucional e intencional que tem nos valores simbólicos e funcionais a condição para a construção do sentido e para circular socialmente, desencadeando processos de conhecimento". A construção de sentido e a circulação social, condicionadas aos valores simbólicos e funcionais, propõem a ideia de que a informação não é uma questão individual, mas de ordem social e cultural. Outro ponto perceptível é que, ao colocar os valores simbólicos, Lara sugere que os elementos capazes de produzir sentido não podem ser reduzidos ao lingüístico. Este ponto merece destaque uma vez que a apreensão da informação na charge não se dá apenas pelo verbal.

Uma das principais características da charge, assim como qualquer narrativa, é a referência a outros eventos e textos, cabendo àquele que a vê estabelecer os elos para construção do sentido proposto pelo chargista. Se a interação entre autor, charge e aquele que vê não se estabelece, as "informações contidas na charge não se convertem em signos, não são percebidas e, nesse caso, não entram no circuito comunicacional” (FLÔRES, 2002, p. 11). 0 interdiscurso e a intertextualidade caracterizadores da charge a aproximam da ideia de informatividade de Capurro (2007) e de Capurro e Hjørland (2007) e do entendimento de informação como um processo construtivo sugerido por Lara (2008). Portanto, a apreensão da informação na charge, se ocorrer efetiva compreensão por aquele que a vê, se torna um processo informativo em que um usuário possui uma estrutura prévia de conhecimento a partir da qual interpretará a mensagem, isto é, identificará a informatividade do documento segundo seus próprios critérios de relevância.

Tratando-se da identificação de conteúdo informativo da charge, vale a pena trazer alguns questionamentos sobre a limitação do conceito de leitura de imagem e apontar algumas implicações na análise documentária. Leitura de imagem, portanto de charge, já é uma noção presente na literatura da ciência da informação, tanto no sentido de apreensão da informação imagética quanto na etapa da documentação, a leitura documentária. A noção de leitura de charge está presente também na literatura, como, por exemplo, a obra de Flôres (2002) cuja expressão já figura o título.

Sgarbi (2016) chama atenção para o fato de que a leitura de imagens é uma metáfora profundamente naturalizada, de tal modo que as pessoas têm dificuldade de escapar dela em seus

6 LARA, M. L. G. de. A ciência da informação e a teoria dos termos. In: SIMPOSIO IBERO AMERICANO DE TERMINOLOGIA, 9, 2006, Barcelona; CABRÉ, M. T.; ESTOPÁ,R.; TEBÉ, C. (Org.). Actas del...: La terminología en el siglo XXI: contribuición a la cultura dela paz, la diversidad y la sostenibilidad. Barcelona [España]: Universidad Pompeu Fabra, Institut Universitari de Lingüística Aplicada, 2006. p. 341-347. 
discursos e em suas ações, até mesmo quando chamada atenção para isso. 0 autor explica que imagem e texto são de natureza diferentes e inventadascriadas utilizando distintos elementos básicos que formatam sua linguagem. Nas palavras do autor,

[..] é bom se ter em mente que há uma infinidade de tipos diferentes de imagem [...] assim como existem variados e diferentes tipos de texto, mas, por enquanto, nos deteremos nos elementos básicos de imagens e textos, apenas enfatizando que, enquanto as imagens podem ser inventadascriadas por variados elementos básicos [luz, cor, traço, tinta...], os diferentes e variados tipos de textos são inventadoscriados a partir da palavra, e esse é um ponto fundamental para aprofundarmos a leitura de imagens como metáfora, lembrando, ainda, que estamos falando de imagens inventadascriadas por mulheres e homens, e não as que existem como a visualidade do mundo em que vivemos (SGARBI, 2016, p. 15, colchetes e grifo do autor).

Sgarbi (2016), então, cunha o termo vistura7 como uma confrontação ao uso de leitura para expressar a interpretação de imagens ou das narrativas que delas podem surgir. A noção de vistura, contudo, não busca a dicotomia com a leitura. A proposta é outra compreensão das imagens enquanto linguagens. Uma marca de diferença entre leitura e vistura é que "aquela é feita, na esmagadora maioria dos casos [...], de forma linear, ou seja, a compreensão da leitura pressupõe que as frases sejam lidas linearmente, enquanto a vistura não pressupõe um ponto inicial, o vistor pode começar sua imersão na imagem por qualquer ponto dela" (SGARBI, 2015, p. 17). Além disso, ao contrário da leitura, a vistura não pressupõe o domínio de um código específico. 0 vistor pode lançar mão de todo seu acervo imagético para ver e interpretar a imagem.

A noção de vistura ainda está em fase de amadurecimento. Por isso, sua importação para a ciência da informação ainda não se evidenciou ainda. Porém, a ciência da informação, como área de investigação da dinâmica da informação, pode e deve contribuir para o sentirinventarpensar a noção de vistura.

\subsubsection{Terminologia da área}

0 estado de sistematização metodológica da área é a próxima variável elencada por Lara (1993). São muitas as evidências de sistematização metodológica e entre elas está a consolidação da terminologia de uma área do conhecimento. Lara destaca as facilidades e as dificuldades decorrentes

7 A noção de vistura tem sido sentida inventada pensada no grupo Linguagens desenhadas e educação, afiliado à Faculdade de Educação (FE) da Universidade do Estado do Rio de Janeiro (UERJ). 
da precisão terminológica de cada área. As atividades documentárias são facilitadas em uma área onde haja maior precisão terminológica, ao passo que, em áreas de menor precisão, apresenta maiores dificuldades na representação de documentos.

Não é possível dizer que há uma comunidade discursiva em torno da charge. Porém, enquanto objeto de investigação de diferentes áreas do conhecimento, é possível supor que haja alguma linguagem de especialidade ${ }^{8}$ para se referir à charge e aos elementos em torno desse desenho de humor. Estudos anteriores apontam evidências de imprecisão conceitual e variações em trocas discursivas em diferentes esferas de comunicação (GAWRYSZEWSKI, 2008; GOMES, 2015; PELÁEZ MALAGÓN, 2002). A imprecisão conceitual é uma evidência de que, na linguagemda especialidade, há pouca consistência terminológica.

Contudo, vale a pena apontar a limitação no uso de signos linguísticos para nomear imagens. A primazia da linguagem verbal torna difícil que se reconheçam como precisas as informações imagéticas. Dessa forma, tratando-se de charge, mais uma vez o problema da transcodificação vem à tona, uma vez que a linguagem verbal não esgota as possibilidades da imagem.

\subsubsection{A instituição de custódia da charge}

Lara (1993) apresenta a instituição em que a análise documentária se desenvolve como 0 contexto geral dentro do qual esse processo se insere. Podemos expandir essa discussão se olharmos as instituições como organizações. Assim, a discussão traz um olhar sobre os objetivos e recursos dessas unidades de informação. Etzioni (apud HALL, 2004, p. 28) define as organizações como "entidades sociais (ou agrupamentos urbanos) deliberadamente criadas e recriadas para atingir metas específicas". Nesta compreensão, as instituições em foco são criadas e recriadas a fim de manter um acervo visando ao fornecimento de serviços de informação, como preservação e recuperação de charges.

Como qualquer organização, as instituições de custódia de charges dispõem de recursos que passam por processos a fim de obter produtos e serviços. De acordo com Maximiano (2008), os recursos das organizações são pessoas, materiais, ativos financeiros, informação, espaço e tempo. Estes recursos sofrem operações dispostas na divisão do trabalho. Tudo isso, para resultar

8 Uma língua de especialidade diz respeito à língua utilizada pelas pessoas que compõem um domínio e é caracterizada pelo uso de meios de expressão lingüística particulares (LARA, 2002). 
em produtos e em serviços. As diferentes instituições são formadas por pessoas, uma vez que são unidades sociais. As diversidades possíveis entre as pessoas de uma instituição confluem para que a charge seja documentada de formas diferentes. Portanto, as pessoas constituem mais um aspecto relevante desta variável.

Para alcançar seu fim, as organizações estabelecem missão, objetivos e visão como elementos de planejamento estratégico. Fundamentadas nestes princípios, as organizações planejam o uso dos recursos e os processos para alcançar seus objetivos com eficiência e com eficácia. Nesse sentido, as diferentes instituições de custódia de charge podem assumir diferentes missões, objetivos e visões. Por exemplo, uma empresa jornalística manterá um acervo de charge e o usará de forma diferente de uma biblioteca escolar ou de um museu popular. Portanto, missão, objetivos e visões institucionais constituem-se em aspectos relevantes da variável instituição.

Cumpre também destacar que os objetivos, a política e o manual de indexação devem estar alinhados ao planejamento estratégico das organizações. Em outros termos, estes elementos presentes em qualquer sistema informativo documental devem contribuir para que a instituição alcance seus objetivos.

Uma vez que as pessoas figuram um aspecto variante da instituição, é possível dizer que as atividades documentárias são carregadas de valores. Para evitar que tais valores sejam aleatórios e dependentes das escolhas pontuais e arbitrárias dos indexadores, Lara e Tálamo (2007) recomendam o recurso de políticas institucionais que assegurem a possibilidade de interpretações razoavelmente respaldadas nas formas compartilhadas de compreensão da informação.

As políticas e os manuais de indexação determinam como se dá a representação documentária, interferindo em todo processo de organização e de recuperação de documentos no sistema. Na literatura especializada, podem ser encontradas propostas de abordagens para diferentes documentos de linguagem imagética. Lancaster (2004) faz uma revisão de literatura sobre indexação em base de dados de imagens em geral, onde indica estudos de métodos de tratamento temático de imagens. Shatford (1986) provê bases teóricas para a indexação de pinturas. Maimone e Tálamo (2009) propõem metodologias para a representação de imagens artístico-pictórias em museus. Smit (1989; 1996), Alves e Valerio (1998), Manini (2002) e Moreiro González e Robledano Arillo (2003) estabelecem princípios e metodologias para análise documentária de fotografias. Observando um nicho mais específico de uso, Souza (2013) reflete sobre um esquema teórico para indexação, em banco digitais de fotografias, visando a usos na publicidade. Bovey (1995) desenvolve um tesauro para auxiliar a representação de 
cartuns. Ribeiro e Cordeiro (2007) sugerem uma abordagem para representação de caricaturas. Wu (2013) propõe um esquema para auxiliar a indexação de charges. Ainda poderiam ser citados outros exemplos de linguagens imagéticas, como cartografias, cinema e plantas baixas. Portanto, é possível sublinhar abordagens de documentação nas instituições mantenedoras de charge. A diversidade de teorias e de metodologias sugere variações e adaptações aos diversos contextos, evidenciando a influência da instituição sobre a análise documentária da charge.

0 Museu Virtual do Cartoon (2010) disponibiliza, em seu sítio, uma lista de galerias e de museus do mundo inteiro mantenedores de charges, de caricaturas e de cartuns em seus acervos. ChappleSokel (1996) discute 0 acesso a charges e a cartuns em arquivos, em bibliotecas e em museus do mundo todo. Cammarata (2008) traz uma lista de dezenove coleções de charges disponibilizadas na web. As organizações que mantêm esses estoques de informação são exemplos da variável instituição. Cada uma delas tem missão, visão, valores, objetivos e recursos, assim como pessoal e clientela próprios. Cabe ainda observar que alguns desses acervos estão desterritorializados, implicando um alcance mais global de seus documentos e novos desafios para a organização e a representação de charge considerando a diversidade dos contextos de recepção e de uso dos documentos.

Além dos recursos supracitados, também é necessário apontar os recursos financeiros, materiais e tecnológicos. Todos esses recursos influem sobre a análise documentária, na medida em que possibilitam e/ou impossibilitam instrumentos para as atividades documentárias e para a recuperação de documentos.

Outro aspecto das instituições são os seus usuários. De acordo com Lara (1993), é a instituição que delimita seu usuário e estabelece seu perfil, aspecto desta variável que será discutido na próxima subseção.

\subsubsection{0 usuário da charge}

0 usuário é a quarta variável apontada por Lara (1993). Ao pensar o usuário, não é possível deixar de pensar no uso. Nesta subseção, ora se fala em usuário ora em uso. São muitas as possibilidades de se discutir o usuário. Para iniciar o debate, a análise traz a questão sobre os usos possíveis da charge: "para quem/para que a charge é informativa?"

A apresentação do conceito de informação adotado nesta pesquisa se torna importante na medida em que contribui para elucidação, por meio de associações, dos aspectos informativos da 
charge. No entanto, neste estudo, substitui-se a pergunta "o que é informação" por "para que serve a informação?" (CAPURR0,1991). A preocupação é saber para que a charge é informativa. Pressupõese, então, que, mais do que a informação, é "a informatividade que permite entrever o jogo intertextual que caracteriza os processos de recepção determinando os critérios de relevância para que algo seja considerado informativo" (ORTEGA; LARA, 2010). Dessa forma, a discussão aqui privilegia o debate sobre informatividade, ou seja, sobre a capacidade de a charge informar.

Entre as possibilidades de se compreender a informatividade da charge, está a análise de sua materialidade a partir dos níveis do ser documento, sugeridos por Rendón Rojas (2005, p. 127-130). 0 autor distingue diferentes níveis de ser documento segundo a atividade cognitiva a que o documento dá lugar e da qual é produto. Por meio desses níveis, o autor propõe o percurso para que um objeto se torne um documento no domínio da bibliotecología9. Apresentam-se a seguir elementos dos contextos de produção e de uso da charge, com o intuito de se estabelecer uma associação aos níveis de ser documento.

Em um primeiro nível se encontra o objeto tal e como é, sem que haja uma intervenção para sua aparição ou uma intencionalidade de fazê-lo documento. No primeiro nível, se tem o objeto em si (RENDÓN ROJAS, 2005). 0 uso comum da charge está relacionado à sua função como gênero de opinião. Em meio a esse contexto, a charge pode ser vista como "uma crítica político-social atravésda qual o chargista expressa graficamente, com humor e ironia, seu ponto de vista sobre determinadas situações cotidianas" (NICOLAU, 2010, p. 6). Dessa forma, no primeiro nível de ser documento, se tem a charge em si, cuja finalidade é a expressão da opinião do chargista sobre determinado evento através do gênero de opinião.

Os usuários de charge enquanto objeto em si são os leitores de jornal e de revistas, os usuários das redes sociais e os demais que veem as charges nos diferentes recursos de informação em que aparecem. Este usuário não costuma ser especialista e não busca na charge informações, tampouco referências a determinado contexto ou situação. Dessa forma, a função da charge, para esse usuário, não é informativa nem referencial, mas de fruição. Trata-se de um uso mais livre e desinteressado. A princípio, a ciência da informação não oferece serviços para usuários de fruição, uma vez que

9 A opção por adotar bibliotecología, termo castelhano utilizado por Rendón Rojas, tem a intenção de evitar as possíveis implicações epistemológicas que a tradução para os termos portugueses brasileiros biblioteconomia ou ciência da informação poderia exigir. 
os produtos documentários têm a função referencial. Porém, um estudo de usuário pode indicar a demanda por esse tipo de serviço bem como sugerir possibilidades de implantá-lo.

No segundo nível, aparece o mesmo objeto com informações para especialistas de determinada disciplina, os quais, visando à obtenção de informação, estudam e investigam as mensagens apresentadas por esse objeto. 0 objeto, nesse nível, se converte em documento para o trabalho do especialista, deixa de ser um objeto em si para ser um objeto para outro. Fisicamente pode constituir 0 mesmo objeto, porém em uma dimensão simbólica incorpora um significado adicional em relação ao que possuía quando era somente objeto em si. (RENDÓN ROJAS,2005).

Neste nível, a variável usuário sofre algumas consequências se analisada desde a noção de domínio. Mai (2005) designa como domínio um grupo de pessoas que compartilham objetivos, como, por exemplo, uma área de especialidade, um campo de literatura ou um grupo de pessoas trabalhando juntas em uma organização. A ideia de domínio desse autor vai além de uma disciplina acadêmica e está intimamente ligada às atividades humanas. Segundo Hjørland e Albrechtsen (1996), o trabalho de um domínio reflete sobre a organização do conhecimento, a estrutura e os padrões de cooperação, a linguagem e os meios de comunicação, nos sistemas de informação e os critérios de relevância.

A charge é um documento relevante para diferentes comunidades disciplinares, sendo, por exemplo, objeto de estudos nos domínios das artes visuais, das ciências sociais, da comunicação social, da comunicação visual, da educação, da filosofia da arte, da linguística e da literatura (GOMES, 2013). Como exemplo, se pode citar a lista de referências do artigo de revisão sobre o conceito de charge, de Gawryszewski (2008), onde figuram trabalhos de conclusão apresentados em programas de pós-graduação em arte, em comunicação e semiótica, em comunicação social, em história social e em língua portuguesa. Flôres (2002) defende o valor histórico da charge como repositório de forças ideológicas em ação, como instrumento de reflexão e projeção das principais concepções e dos pontos de vista em circulação em determinada sociedade. Desse modo, a charge passa ao segundo nível de ser documento quando, por exemplo, para um historiador, deixa de ser apenas a expressão de uma crítica de um chargista para ser um indício das principais ideias e opiniões circulantes em determinado contexto sócio-histórico. Por exemplo, Diniz e Gomes (2014) usam caricaturas e charges para análise da modernização do carnaval carioca e da cidade do Rio de Janeiro, durante o início do século XX.

A relevância levanta um ponto na discussão a respeito do objeto para outro, o segundo nível do documento de acordo com a proposta de Rendón Rojas (2005). Saracevic (2009) sublinha a relevância como uma noção humana e não do sistema. Portanto a relevância está intimamente ligada ao usuário 
e, por consequência, ao uso. Hjørland (2001) afirma que a melhor análise temática é aquela que faz 0 melhor prognóstico quanto ao uso futuro do documento.

0 documento configura um terceiro nível quando é tratado por um profissional da informação e este se encarrega de convertê-lo em um documento bibliotecológico. Devido à ação desse profissional, ao inserir um documento em um sistema informativo documental, a informação é agregada ao documento no processo de organização e de representação do conhecimento, com o propósito de recuperação por um usuário. 0 documento, nesse sistema, tem um ser agregado que não tinha antes. A ação do profissional da informação dá um novo sentido ao documento inicial porque o coloca num contexto específico. Somente depois dessa ação, o documento adquire personalidade dentro do sistema informativo documental (RENDÓN ROJAS, 2005). No contexto do objeto desta pesquisa, os profissionais da informação tratam a charge a fim de the agregar valor informativo para determinado domínio segundo estruturas objetivas do sistema informativo documental.

É possível visualizar o efeito do ser documento em terceiro nível de Rendón Rojas (2005) no que González de Gómez (1993) denominou como fontes e canais de informação agregados.

Hoje a busca de uma informação que seja uma resposta pertinente e relevante às nossas perguntas requer a reconstrução de um complexo cenário onde sejam agregadas as populações de fontes e canais de informação, de modo a permitir processos seletivos, organizados e econômicos de busca e recuperação. (GONZÁLEZ DE GÓMEZ, 1993, p. 216).

No nível do documento bibliotecológico, estabelecem-se relações da charge com outros documentos de modo a permitir uma diversidade de possibilidades para recuperá-la e, portanto, de novos usos. Em um sistema informativo documental, é possível agregar, por exemplo, as populações de charges referentes a determinados assuntos, produzidas por determinado jornal ou que figuram determinado personagem ou objeto.

\subsubsection{A formação e as referências do documentalista}

A formação e o quadro de referência do documentalista, incluindo sua ideologia, configuram uma variável que determina todos os processos de análise documentária (LARA, 1993). De acordo com Fujita (2004), o objetivo do documentalista é representar o assunto de um documento por meio de termos significativos, para que seja possível a recuperação pelos usuários interessados. A autora afirma que o êxito desse processo depende das habilidades e dos conhecimentos prévios do profissional, necessários à atividade documentária. 
Como em qualquer mensagem, o conhecimento prévio é fundamental para a compreensão da charge, conforme destacou Flôres (2002). A interpretação da charge, desse modo, consiste em um processo informativo de contextualizar o conhecimento objetivado no documento, a partir de um pressuposto já conhecido. Quanto maior for esse conhecimento pressuposto, maiores a chance de esse processo informativo durante a análise documentária alcançar o sucesso. Esta discussão suscita questões sobre quais conhecimentos e competências o documentalista deve possuir para tratar a charge em um sistema informativo documental.

Gawryszewski (2008, p. 16) afirma que o riso ou o prazer na leitura de uma charge ou de uma caricatura só existe "se houver certa cumplicidade, uma possibilidadede acordo entre o desenhista e o leitor". Cunha (1990, p. 71) discute o problema da ideologia do analista documentário na execução de suas atividades profissionais. Para a autora, a negação do componente ideologia em análise do texto para fins documentais "é não colocar em questão o papel do indivíduo no processo de produção, consumo e tradução do conteúdo para o todo/conceito/palavra-chave". Ao mesmo tempo, a autora alerta que essa postura também consiste em negar que a linguagem do discurso ou da linguagem documentária é aquisição, construção e instrumento "elaborado respectivamente pela sociedade por e para um grupo social, refletindo, em ambos os casos, o pensamento e os interesses dominantes". Estas questões provocam discussões a respeito da postura ética para a análise documentária da charge, assim como as limitações de tal processo, considerando as diferenças entre os contextos ideológicos de produção e de uso.

\section{CONCLUSÃO}

Este trabalho apresentou uma reflexão sobre a charge no escopo da análise documentária em sistemas de informação. A intenção foi investigar a charge como um tipo de documento, buscando identificar caraterísticas e elementos de representação e organização do conhecimento para recuperação de informação. Foi centrado na análise e interpretação das variáveis do processo geral da análise documentária aplicadas à charge.

A charge tem sido investigada por diversas áreas do conhecimento e utilizada em diferentes domínios de atividades por ser um instrumento poderoso para intervenção na realidade, para reprodução de discursos e para educação da população.

A presente pesquisa foi delineada no contexto da ciência da informação, considerando a charge enquanto objeto informativo integrante de sistemas de recuperação de documentos tradicionais, 
vislumbrando o uso das charges como documento passível de investigação na academia e pela sociedade em geral.

Como aspectos conclusivos podemos destacar que a universalidade, a atemporalidade, a neutralidade e a imparcialidade no caso da charge devem ser vistas como características utópicas a serem consideradas, o que inviabilizaria uma proposta para a análise documentária com todos esses atributos. No entanto, consideramos que o conhecimento da estrutura narrativa e de como se dá produção sígnica podem contribuir para a elaboração de estratégias visando especificamente a análise documentária de charges. Por outro lado, pensar a charge enquanto possibilidades de construção de narrativas abrem espaço para a charge ser vista como obra aberta na interpretação, o que revela a complexidade do tratamento da charge no âmbito da representação e organização do conhecimento.

É importante destacar que a caracterização da charge como documento, através de uma proposta de variáveis da análise documentária em geral proposta para recuperação documentos, exigiu um olhar alerta para a noção de informação. Destacamos também que os procedimentos da análise documentária permanecem como metodologia profícua e como base teórica para vários tipos de documentos. Reconhecemos, porém, a necessidade de atualização e de adaptação da análise documentária ao contexto do tratamento específico da charge como material especial.

Para finalizar, ressaltamos a pertinência de que a proposta de diálogo com outras correntes teóricas da ciência da informação. Nesse sentido, é relevante o convite de Lara (2008) para interlocução e para debate visando à compreensão do uso social da informação e à melhoria de práticas da curadoria da informação em sistemas informativos.

\section{REFERÊNCIAS}

ALVES, Mônica Carneiro; VALERIO, Sergio Apelian. Manual para indexação de documentos

fotográficos. Rio de Janeiro: Fundação Biblioteca Nacional, Departamento de Processos Técnicos, 1998.

ARAÚJO JÚNIOR, Rogério Henrique de. Precisão no processo de busca e recuperação da informação. Brasília, DF: Thesaurus, 2007. (Série Ciência da Informação e da Comunicação).

BOVEY, J. D. Building a thesaurus for a collection of cartoon drawings. Journal of information science, Los Angeles, CA, [United States of América], v. 21, n. 2, p. 115-122, 1995.

CAMMARATA, Paul. Editorial cartoons on the web: picturing politics. College research library news, Chicago, II, v. 69, n. 9, p. 536-539, 2008. 
CAPURR0, Rafael. Epistemología y ciencia de la informacion. Enl@ace, Maracaibo [Venezuela], v. 4, n. 1, p. 11-29, ene./abr 2007.

CAPURR0, Rafael. Foundations of information science: review and perspectives. In: INTERNATIONAL CONFERENCE ON CONCEPTIONS OF LIBRARY AND INFORMATION SCIENCE, Finland, 1991.

Proceedings... Tampere: University of Tampere, 1991. Disponível em: http://www.capurro.de/ tampere91.htm. Acesso em: 16 jul. 2007.

CAPURRO, Rafael; HJØRLAND, Birger. 0 conceito de informação. Tradução de Ana Maria Pereira Cardoso, de Maria da Glória Achtschin Ferreira e de Marco Antônio de Azevedo. Perspectivas em ciência da informação, Belo Horizonte, MG, v. 12, n. 1, p. 148-207, jan./abr. 2007.

CHAPPLE-SOKOL, Angie. Indexing editorial cartoon. Special libraries, v. 87, n. 1, p. 21-31, 1996.

CINTRA, Anna Maria Marques, et al. Para entender as linguagens documentárias. São Paulo: Editora Polis, 1994.

CUNHA, Isabel Maria Ribeiro Ferin. Do mito à análise documentária. São Paulo: EDUSP, 1990. (Teses, 11).

DINIZ, Reinaldo Ramos; GOMES, Thulio Pereira Dias. Indícios de uma pedagogia de Momo: o papel pedagógico dos chargistas na modernização do Carnaval. Scientiarum historia, Rio de Janeiro, v. 7, p. 1-8, 2014.

FLÔRES, Onici. A leitura da charge. Canoas, RS: Ed. ULBRA, 2002.

FOUCAULT, Michel. As palavras e as coisas: uma arqueologia das ciências humanas. Tradução de Salma Tannus Muchail. 8. ed. São Paulo: Martins Fontes, 1999.

FUJITA, Mariângela Spotti Lopes. A leitura documentária na perspectiva de suas variáveis: leitortexto-contexto. Datagramazero, Rio de Janeiro, v. 5, n. 4, Artigo 01, ago. 2004.

GARCÍA GUTIÉRREZ, Antonio Luis. Estructura linguística de la documentación: teoría y método. Murcia [España]: Universidade de Murcia, Secretariado de Publicaciones, 1990.

GARDIN, Jean-Claude. Document analysis and linguist theory. Journal of documentation, Bradford, [United Kingdon], v. 19, n. 2, p. 137-168, 1973.

GAWRYSZEWSKI, Alberto. Conceito de caricatura: não tem graça nenhuma. Domínios da imagem, Londrina, PR, v. 1, n. 2, p. 7-26, maio 2008.

GOMES, Thulio Pereira Dias. Temas e questões em análise documentária de charge. 2013. 65 f. Trabalho de Conclusão de Curso-(Graduação em Biblioteconomia). Faculdade de Administração e Ciências Contábeis, Universidade Federal do Rio de Janeiro. Rio de Janeiro, 2013.

GOMES, Thulio Pereira Dias; GUEDES, Vânia Lisboa da Silveira; SANTOS, Maria José Veloso da Costa. Interferências dos contextos de produção e de uso na análise documentária de charge. In: RIBEIR0, Fernanda; CERVEIRA, Maria Elisa (Org.). Informação e/ou conhecimento: as duas faces de Jano. Porto [Portugal]: Faculdade de Letras da Universidade do Porto, 2013a. p. 245-263. 
GONZÁLEZ DE GÓMEZ, Maria Nélida. Representação do conhecimento e conhecimento da representação: algumas questões epistemológicas. Ciência da informação, Brasília, DF, v. 22, n. 3, p. 217-222, set./dez. 1993.

GUIMARÃES, José Augusto Chaves. A análise documentária no âmbito do tratamento da informação: elementos histórico-conceituais. In: RODRIGUES, Georgete Medleg; LOPES, Ilza Leite (Org.).

Organização e representação do conhecimento na perspectiva da Ciência da Informação. Brasília, DF: Thesaurus, 2003. p. 100-117. (Estudos Avançados em Ciência da Informação, 2).

GUIMARÃES, José Augusto Chaves. Abordagens teóricas de tratamento temático da informação: catalogação de assunto, indexação e análise documenta. Ibsersid, Zaragoza [España], v. 3, p. 105117, 2009.

HALL, Richard H. Organizações: estruturas, processos e resultados. 8. ed. São Paulo: Pearson Prentice Hall, 2004.

HJØRLAND, Birger. Toward a theory of aboutness, subject topically, theme, domain, field, content... and relevance. Journal of the American Society for the Information Science and Technology, Hoboken, NJ, [United States of America], v. 52, n. 9, p. 774-778, 2001.

HJØRLAND, Birger. What is knowledge organization (KO)?. Knowledge Organization, Frankfurt, [Germany], v. 35, n. 3, p. 86-101, 2008.

HJØRLAND, Birger; ALBRECHTSEN, Hanne. Toward a new horizon in information science: domainanalysis. Journal of the American Society of Information Science, Hoboken, NJ, [United States of America], v. 46, n. 6, p. 400-425, 1995.

KOBASHI, Nair Yumiko. Análise documentária e representação da informação. Informare, Rio de Janeiro, v. 2, n. 2, p. 5-27, jul./dez.1996.

LANCASTER, F. W. Indexação e resumos: teoria e prática. Tradução de Antonio Agenor Briquet de Lemos. 2 ed. rev. atual. Brasília, DF: Briquet de Lemos, 2004.

LARA, Marilda Lopes Ginez de. A representação documentária: em jogo a significação. 1993. 133 f. Dissertação (Mestrado em Ciências da Comunicação) - Escola de Comunicação e Artes, Universidade de São Paulo, São Paulo, 1993.

LARA, Marilda Lopes Ginez de. Conceitos de Organização e Representação do Conhecimento na ótica das reflexões do Grupo Temma. Informação e Informação, Londrina, PR, v. 16, n. 3, p. 92-121, jan. jun. 2011.

LARA, Marilda Lopes Ginez de. Informação, informatividade e Linguística Documentária: alguns paralelos com as reflexões de Hjorland e Capurro. Datagramazero, Rio de Janeiro, v. 9, n. 6, Artigo 01, dez. 2008.

LARA, Marilda Lopes Ginez de. 0 processo de construção da informação documentária e o processo de conhecimento. Perspectivas em ciência da informação, Belo Horizonte, MG, v. 7, n.2, p. 127-140, 2002. 
LARA, Marilda Lopes Ginez de; TÁLAMO, Maria de Fátima Gonçalves Moreira. Uma experiência na interface linguística documentária e terminologia. Datagramazero, Rio de Janeiro, v. 8, n. 5, out. 2007.

MAI, Jens-Erik. Analysis in indexing: document and domain centered approaches. Information Processingand Management, Oxford, [United Kingdon], v. 41, p. 599-611, 2005.

MAIMONE, Giovana Deliberali; TÁLAMO, Maria de Fátima Moreira. Metodologias de representação da informação imagética. Transinformação, Campinas, SP, v. 21, n. 3, p. 181-196, set./dez. 2009.

MANINI, Miriam Paula. Análise documentária de fotografias: um referencial de leitura de imagens fotográficas para fins documentários. 2002. 232 f. Tese (Doutorado em Ciências da Comunicação)Escola de Comunicação e Artes, Universidade de São Paulo, São Paulo, 2002.

MAXIMIANO, Antonio Cesar Amaru. Introdução à administração. 7. ed. rev. ampl. São Paulo: Atlas, 2008.

MOLLICA, Maria Cecília de Magalhães; GUEDES, Vânia Lisboa da Silveira. Mudança no fluxo informacional e gêneros discursivos. In: ALBAGLI, Sarita (Org.). Fronteiras da ciência da informação. Brasília, DF: IBICT, 2013. p. 216-235.

MOREIRO GONZÁLEZ, José Antonio; ROBLEDANO ARILLO, Jesús. 0 conteúdo da imagem. Tradução de Leilah Santiago Bufrem. Curitiba, PR: Editora UFPR, 2003. (Série Pesquisa, n. 86).

MUSEU VIRTUAL DO CARTOON. Museus e galerias. 2010. Disponível em: <http://www. cartoonvirtualmuseum.org/i_galerias_f.htm>. Acesso em: 19 jun. 2014.

NICOLAU, Marcos. As tiras e outros gêneros jornalísticos: uma análise corporativa. Revista eletrônica temática, João Pessoa, PB, v. 7, n. 2, fev. 2010.

ORTEGA, Cristina Dotta; LARA, Marilda Lopes Ginez de. A noção de documento: de Otlet aos dias de hoje. Datagramazero, Rio de Janeiro, v. 11, n. 2, artigo 03, abr. 2010.

PELÁEZ MALAGÓN, José Enrique. El concepto de caricatura como arte en el siglo XIX. Sincronía, Guadalajara, Jal. [México], Primavera, 2002.

RENDÓN ROJAS, Miguel Ángel. Bases teóricas y filosóficas de labibliotecología. 2. ed. México: UNAM, Centro Universitario de Investigaciones Bibliotecológicas, 2005.

RIBEIR0, Rita de Cássia Souza; CORDEIR0, Rosa Inês de Novais. A caricatura na perspectiva da representação documentária. In: ENCONTRO NACIONAL DE PESQUISA EM CIÊNCIA DA INFORMAÇÃO, 8, Salvador, BA, 28 a 31 de outubro de 2007. Anais... Salvador: UFBA, 2007.

SARACEVIC, Tefko. Relevance: a review of the literature and a framework for the thinking on the notion in information science. In: BRAGA, Gilda Maria; PINHEIRO, Lena Vania Ribeiro (Org.). Desafios do impresso ao digital: questões contemporâneas de informação e conhecimento. Brasília, DF: IBICT; UNESC0, 2009. p.15-168. 
SGARBI, Paulo. Vistura: uma noção em tecedura coletiva cotidiana. LINGUAGENS DESENHADAS E EDUCAÇÃO; SGARBI, Paulo (org.). Vistura: as imagens de todo dia. Rio de Janeiro: LINGDES, 2016. No prelo.

SHATFORD, Sara. Analyzing the subject of a Picture: a theoretical approach. Cataloging \& classification quartely, New York, N.Y, [United States of America], v. 6, n. 3, p. 39-62, 1986.

SMIT, Johanna W. A análise da imagem: um primeiro plano. In: GRUPO TEMMA; SMIT, Johanna W. (Coord.). Análise documentária: a análise da síntese. 2. ed. Brasília, DF: IBICT, 1989. p. 102-113.

SMIT, Johanna W. A representação da imagem. Informare, Rio de Janeiro, v. 2, n. 2, p. 28-36, jul./ dez. 1996.

SMIT, Johanna W. Grupo TEMMA. In: GUIMARÃES, José Augusto Chaves; DODEBEI, Vera. (Org.). Desafios e perspectivas científicas para a organização e representação do conhecimento na atualidade. Marília, SP: Sociedade Brasileira de Organização do Conhecimento; Fundação de Desenvolvimento da Pesquisa, 2012. p. 222-226.

SOUZA, Jóice Cleide Cardoso Ennes de. Banco de imagens: abordagem teórica conceitual de representação de fotografias para uso na publicidade. 2013. 284 f. Tese (Doutorado em Ciência da Informação) - Escola de Comunicação, Universidade Federal do Rio de Janeiro. Rio de Janeiro, 2013.

TEIXEIRA, Luiz Guilherme Sodré. Sentidos do humor, trapaças da razão: acharge. Rio de Janeiro: Edições Casa de Rui Barbosa, 2005. (Coleção FCRB, Série Estudos, 2).

VANOYE, Francis. Usos da linguagem: problemas e técnicas na produção oral e escrita. Tradução de Clarisse Madureira Sabóia et al. São Paulo: Martins Fontes, 2002.

VIEIRA, André Guirland. Do conceito de estrutura narrativa à sua crítica. Psicologia, Porto Alegre, RS, v. 14, n. 3, p. 599-608, 2001.

WU, Yejum. Indexing historical, political cartoons for retrieval. Knowledge Organization, Frankfurt, [Germany], v. 40, n. 3, p. 283-294, 2013. 